\title{
The Perils of Participation: The Effect of Participation Messages on Citizens' Policy Support
}

Geneviève Risner and Daniel Bergan

Michigan State University

\begin{abstract}
While scholars have found several benefits to citizens, government, and society resulting from participatory policy processes, other research suggests that citizens are apathetic and uninterested in participating in policy-making. Also, in some cases, knowing that similar others participated in making a decision can decrease support for the result. The current research attempts to determine whether knowledge that similar citizens participated in public transportation policymaking or elites designed a transit policy affects support for the policy as well as general support for the policy process. Results from a survey experiment suggest that who participates matters. Citizens do not want "people like them" developing public transportation policies. These findings pose implications for the promotion of participatory processes.
\end{abstract}

\section{Introduction}

Transit agencies face increasing requirements to engage the public in strategic planning. In 2007, the Federal Transit Administration (FTA) proposed a new circular on Environmental Justice (FTA C 4702.1A) that provided guidance on promoting inclusive public participation. The circular stated, "An agency's public participation strategy shall offer early and continuous opportunities for the public to be involved in the identification of social, economic, and environmental impacts of 
proposed transportation decisions" (U.S. Department of Transportation 2007: 21). Additionally, 23 CFR 450.210 mandated that recipients of federal transportation funds have public participation plans that engage the public in long-range, strategic transportation planning (Michigan Department of Transportation 2010). Without such public participation, transit agencies are ineligible for federal funding. As transit professionals seek to implement participatory processes, understanding the effect of the messages used to educate the public that these engagement efforts occurred becomes important for later public support of resulting transit policies.

Aside from receiving federal funding, involving citizens in transportation planning may have several positive effects. First, citizen engagement upholds democratic ideals that "[e]very citizen should have an equal chance to influence government policy" by allowing people an opportunity to voice their opinions (Prothro and Grigg 1960: 282). Second, public participation can improve policy-making (Fishkin 1995). Specifically, discussion can improve decision-making by combining participants' information and enlarging the range of arguments for or against a given policy (Rawls 1971). Third, citizen participation in democratic processes may lead to a more informed citizenry, individual empowerment, constructive communication, and actualization of desired outcomes (Irvin and Stansbury 2004).

Furthermore, the benefits of increased citizen involvement in decision-making may extend beyond the participants and policymakers to the broader society. In particular, "[i]f citizens realize that a particular policy was based on deliberation, they will consider the policy to be more legitimate" (Irvin and Stansbury 2004; Ely 1980: 181). Additionally, civic engagement can increase trust in government (Keele 2007; Putnam 1995) or institutions (Beierle 1999).

Just having the perception that participation occurred, as opposed to being an actual participant, can create positive outcomes. For example, Tyler et al. (1985) found, in an experiment where subjects responded to written scenarios about a city council, that respondents reacted more favorably when the council solicited public input. Thus, merely knowing that other citizens participated directly in designing a policy may result in more satisfaction with policy outcomes and trust in government (Kweit and Kweit 2007).

Although participation in democratic processes may have several positive outcomes, other research suggests that engaging the masses in politics may not be an effective strategy because people simply do not wish to be involved. 'Some scholars suggest that many people do not and prefer not to think about politics on a daily basis (Hibbing and Theiss-Morse 2002). 
The last thing people want is to be more involved in political decisionmaking: They do not want to make political decisions themselves; they do not want to provide much input to those who are assigned to make these decisions; and they would rather not know all the details of the decisionmaking process. (Hibbing and Theiss-Morse 2002: 1)

Many citizens prefer to rely on the guidance of others to make policy-related decisions rather than become engaged in politics themselves. These attitudes suggest that citizens prefer representative government and, more particularly, a "trustee" model of representation, rather than a deliberative form of policy-making. In the trustee model of representation, "[t]he representatives act not as agents of the people but simply instead of them. We send them to take care of public affairs like hired experts, and they are professionals, entrenched in office and in party structures." (Pitkin 2004; 339). Many citizen's believe that "[t]he ideal form of government, ..., is one in which they can defer virtually all political decisions to government officials but at the same time trust those officials...." (Hibbing and Theiss-Morse 2002: 159).

Aside from some individuals' aversion to participation in decision-making, there are other reasons to think that deliberation may actually decrease the legitimacy of policies. Some literature suggests that policies made by other people "just like me" may have a negative consequence on support for a position. When the average citizen does not possess knowledge on a particular topic, he may assume that other people "just like him" also have little knowledge on that topic (Goethals and Nelson 1973). In this case, the fact that similar others participated in developing a policy could have adverse consequences for policy support.

Thus, the literature appears somewhat divided on the issue of participation. One line of scholarship from the area of participatory governance advocates citizen participation in policy-making. When citizens are engaged in policy-making, democratic ideals are upheld and trust is instilled in actual participants as well as those who perceive that other citizens were given an opportunity to voice their opinions. Conversely, another line of scholarship indicates that citizen participation may have adverse consequences. Not only are many citizens apathetic, but they prefer to have elected representatives engage in policy-related discussions and decisions. Furthermore, knowing that a participatory process occurred among similar others could actually decrease support for a policy, especially if the topic addresses an issue on which most people are not knowledgeable (Goethals and Nelson 1973). 
Therefore, this paper raises the following question: How does support for a policy change by knowing similar citizens participated in public transit policy-making or that elites designed a transit policy? This research attempts to answer this question with a survey experiment that followed a community-based participatory process that engaged citizens and elites in a countywide public transportation planning process.

\section{Participation by Proxy}

While scholars have focused on the effects of direct participation on citizen support for policies and other attitudes, other scholars have studied the effects of citizen participation in policy-making on other citizens' attitudes and diffuse support for democratic institutions. Tyler (1990) found that people place importance on perceptions of procedural justice or fairness. When people believed they had an opportunity to share their opinions, even if stating their case did not result in the desired outcome, they felt the process was legitimate and reported positive opinions of actors in the criminal justice system such as judges and police officers (Tyler 1990).

Kweit and Kweit (2007) examined whether these findings applied in a broader community context. They studied the effects of actual participation (engagement in ongoing planning meetings) and perceptions of participation (one's sense that government had made effort to engage community members in planning meetings) on satisfaction with and trust in local government through a phone survey of 600 residents in 2 neighboring communities 5 years after a flood. They found that actual participation caused statistically insignificant decreases in trust in and satisfaction with local government. However, perceptions of participation by others resulted in significant positive relationships with trust and satisfaction with local government. Kweit and Kweit (2007) concluded, “... the symbolic role of participation may be more important than its instrumental role" (407).

Although Kweit and Kweit's (2007) research provides some evidence that perceptions of participation can be important, they do not provide evidence regarding whose input is valued. In the communities that Kweit and Kweit studied, all citizens had an open invitation to participate, but "key leaders were targeted to receive invitations" for community input sessions (Kweit and Kweit 2007: 419). Additionally, one community created a task force of 15 "prominent leaders" per the request of the business community (Kweit and Kweit 2007). As a result, their findings sug- 
gest that the perception that community leaders participated in policy development may be more important than knowing similar others (i.e., ordinary citizens) participated.

\section{Similarity}

Similarity may be one causal mechanism for explaining why perception of participation by other citizens may increase as well as decrease citizen support for a policy. In many cases, similarity has resulted in persuasive outcomes, causing attitude formation or change to align with that of the communicator (Cialdini 2001). Similarity is an effective persuasive tool because "we like people who are similar to us" (Bryne 1971). The effect of similarity on liking has been found for commonalities in age, religion, smoking habits (Evans 1963), names (Garner 2005), political party (Furnham 1996), and attire (Emswiller et al. 1971; Suedfeld et al. 1971). In particular, when the issue in question refers to a value (i.e., evaluation of the goodness or badness of an object, entity, or state of affairs), people are more likely to be influenced by their peer or membership group (Goethals and Nelson 1973; Jones and Gerard 1967).

However, dissimilarity can be persuasive when an issue emphasizes a belief (i.e., can be proven correct or incorrect) (Goethals and Nelson 1973; Jones and Gerard 1967). While this is the first study, to the authors' knowledge, to assess the effect of dissimilarity (similarity) on policy attitudes, several studies support the persuasive power of dissimilar "experts" in contexts dealing with beliefs (Suls et al. 2000; Goethals and Nelson 1973; French \& Raven 1959). In situations where dissimilarity is seen as a providing a strategic advantage, people may form or change an attitude to align with the dissimilar other. Knowledge is one form of dissimilarity shown to result in such effects. Thus, in the case of some complex policies, such as public transportation, knowledge possessed by community elites may create a strategic advantage. When this is the case, the general public should find dissimilarity to be persuasive and rely on the expertise of knowledgeable others to form their opinions.

In policy-making situations where the public "has little knowledge or information," many organizations have used participatory processes (Fishkin n.d.). Some of these local U.S. policy-making situations involve issues such as taxes and spending, energy use, and conservation (Fishkin n.d.). We argue that several other types of policy issues are "often technically complex and value-laden" (see Bierele [1999] for a discussion of environmental policies being technically complex and value-laden, 
pg. 76, emphasis added). Therefore, like most policy issues, local public transportation relates to both beliefs and values.

\section{Hypotheses}

Underlying the foundation of American government is the idea that people should have a voice in the policy-making process. Even when the outcome is counter to what one hoped, when people feel they have been given the opportunity to state their case-creating a fair process-they have more positive feelings toward political actors and a greater sense of legitimacy of the process (Tyler 1990). When people believe elected officials have attempted to engage ordinary citizens in the policy-making process, this fosters a sense of legitimacy (Hibbing and Theiss-Morse 2001). Thus, if community residents are told that other community members "just like them" participated in developing a local policy, we would expect that support for the policy will be greater after people hear a message emphasizing that people like them participated in a policy-making process $(\mathrm{H} 1 \mathrm{a})$.

However, when people believe that the policy topic is one that they-and people like them-are not knowledgeable about, knowing that a participatory process occurred among similar others could actually decrease support for a policy (Goethals and Nelson 1973). In this case, we would expect that support for the policy will decrease after people hear a message emphasizing that people like them participated in a policy-making process $(\mathrm{H} 1 \mathrm{~b})$. These competing frameworks suggest the following research question: How does knowing that similar others participated in a policy-making process affect support for the policy?

In addition, most people do not and prefer not to think about most political issues (Hibbing and Theiss-Morse 2002). Rather, people rely on elected representatives to make policy-related decisions (Pitkin 2004). Additionally, if an issue is related to a belief, dissimilarity will affect a citizen's policy position (Goethals and Nelson 1973). Plus, given Kweit and Kweit's (2007) findings, it is possible the perception of participation by community leaders in policy development is more important than knowing similar others participated. Therefore, for issues that people believe community leaders are better equipped to solve than the average citizen, we would expect support for the policy will be greater after people hear a message emphasizing that community leaders participated in a policy-making process $(\mathrm{H} 2 \mathrm{a})$.

However, citizens have a desire for procedural justice (Tyler 1990); they want to be given the opportunity to voice their opinions (Hibbing and Theiss-Morse 2001). 
When processes are limited to community leader involvement and citizens are excluded from a decision-making process in which they wanted to be involved, we would expect support for the policy would decrease after people hear a message emphasizing that community leaders participated in a policy-making process (H2b). These competing frameworks suggest a second research question: How does knowing that community leaders participated in a policy-making process affect support for the policy?

\section{Method}

The independent variable in this study was participation message type (community members vs. community leaders) with an off-set control group that was not informed about who was involved in designing the public policy. ${ }^{2}$ The dependent variables were verbal support for the policy and behavioral support for the policy. ${ }^{3}$

\section{Sample}

A total of 600 registered voters throughout one Midwestern county served as participants in the current study (female, 66\%). Of participants, 19.7 percent reported an annual household income of less than $\$ 25,000$ per year, 26.8 percent reported earning $\$ 25,001-\$ 50,000$ per year, 17.5 percent reported earning $\$ 50,001-\$ 75,000$ per year, 15.8 percent reported earning more than $\$ 75,000$ per year, and 20.2 percent refused to provide a response or did not know their annual household income. Participants ranged in age from 18-65+. Specifically, 35.8 percent of respondents reported ages of 50-65, 34.8 percent were $65+, 22.2$ percent were 31-49, 3 percent were $18-24,2.7$ percent were $25-30$, and 1.5 percent refused to provide their age.

\section{Procedure}

The survey followed a year-long community-based public transportation planning process. The goal of the planning process was to design a five-year strategic transit plan for Allegan County Transportation (ACT), a rural transportation system that provides approximately 47,000 demand-response rides per year (Allegan County Transportation 2010).

The engagement process employed several phases. Phase 1 included a stakeholder survey and focus groups in which community organizations (e.g., churches, hospitals, employers, nonprofit organizations) were identified and asked to complete an online survey to identify how they are meeting the transportation needs of their clients and recommend improvements to the current ACT system. Following survey completion, six focus groups with a sample of the participants were conducted 
to further discuss their client's transportation needs and make recommendations to improve ACT services (Disability Network/Lakeshore 2012).

Phase 2 consisted of a current rider survey, which sought input on unmet transportation needs of existing ACT riders and provided opportunities for input on ACT improvements; a prospective transit survey, in which community organizations tracked unmet transportation needs of people seeking rides that could not be provided given limited resources; and one-on-one interviews with previous ACT riders with unmet transportation needs, again allowing opportunities for input on recommended changes. Based on analysis of data collected through these two phases, a workgroup of community partners created five transportation options for improvements to ACT (Disability Network/Lakeshore 2012).

Phase 3 included 10 community input sessions that sought feedback from the general public on the 5 options. Community organizations promoted the event through flyers, and a listing of input sessions was posted in two local newspapers. ${ }^{4}$ The results of the input sessions were analyzed and used to create a draft five-year strategic plan for ACT (Disability Network/Lakeshore 2012). The three phases engaged approximately 1,000 local residents and 200 community leaders in focus groups, surveys, and input sessions.

The current experiment was embedded in Phase 4, a phone survey of taxpayers throughout Allegan County, which includes 11 cities and 24 townships. The taxpayer survey was designed to assess a variety of public opinions on local public transportation providers and issues, support for features of the five-year strategic plan, and identify potential, effective messages to use to promote the final plan.

An independent survey firm was hired to conduct phone surveys with registered voters. Phone surveys were conducted during December 2009. Within the context of this survey, participants were asked whether they or someone they know had an unmet transportation need in the past 12 months. After a series of questions related to their attitude toward the transportation system and a variety of potential messages about public transit, respondents were read the following script:

Allegan County Transportation has developed a five-year plan to improve transportation services for residents of Allegan County. It calls for dedicating service hours throughout Allegan County, providing rides to the senior meal sites and offering rides to the only dialysis clinic in the county. Then, respondents were randomly assigned to one of five experimental conditions. $^{5}$ 
1. This plan was created after conducting several meetings, surveys, and input sessions during the past two years with Allegan County residents like you.

2. This plan was created after conducting several meetings, surveys, and input sessions during the past two years with Allegan County community leaders.

3. This plan was created after conducting several meetings, surveys, and input sessions during the past two years with 1,000 Allegan County residents like you.

4. This plan was created after conducting several meetings, surveys, and input sessions during the past two years with 200 Allegan County community leaders.

5. No message.

After being read one of the messages above, respondents were asked to provide a response to the following: "Using a scale from 1 to 5 , with 1 being strongly oppose and 5 being strongly support, please tell me what number best indicates your attitude toward the Allegan County Transportation Five-Year Plan."

Table 1 lists the number of participants assigned to each experimental condition.

Table 1. Number of Participants by Condition

\begin{tabular}{|l|c|c|c|}
\cline { 2 - 4 } \multicolumn{1}{c|}{} & \multicolumn{3}{c|}{ Participant Message Type } \\
\hline Number & Community Members & Community Leaders & Off-Set Control \\
\hline 1,000 or 200 & 122 & 122 & \\
\hline No Number & 126 & 124 & 106 \\
\hline
\end{tabular}

Next, respondents were told that the survey firm was collecting names of people who support public transportation to share with elected officials in their community. Respondents were told their name would not be connected to their survey responses in any way or sold to any other agency; it would be used only to share with elected officials. Then, the researcher asked whether he/she could add the respondent's name to the list of public transit supporters. If the respondent said yes, he/she was asked for his/her first and last name. Finally, questions were asked about demographics (age, income, gender) so their effects could be controlled in the final analysis.

\section{Measures}

\section{Verbal Support for the Policy}

Verbal support for the policy was measured with a five-point Likert scale ( $1=$ "strongly oppose," 5 = "strongly support"). The item asked, "What number best 
indicates your attitude toward the Allegan County Transportation Five Year Plan?" Higher scores reflected more positive support for the policy $(M=3.82, S D=1.07)$.

\section{Behavioral Support for the Policy}

Behavioral support for the policy was measured categorically. Respondents were asked to add their name to a list of public transportation supporters to be shared with their local elected officials. Respondents agreeing to share their name were coded as 1 , all others as 0 ( $59 \%$ agreed to share their name).

\section{Participation Messages}

First, we wanted to compare the effect of "people like you" messages and "community leaders" messages to the control group. In this case, the control message was coded as 1 . Two dummy variables were created. The "people like you" messages ("people like you" and " 1,000 people like you") were coded as 0 . Also, the "community leaders" messages ("community leaders" and "200 community leaders") were coded as 0 .

Next, we wanted to compare the effect of "people like you" messages to "community leaders" messages. Therefore, "people like you" messages ("people like you" and "1,000 people like you") were coded as 1 . Two dummy variables were created. The "community leaders" messages ("community leaders" and "200 community leaders") were coded as 0 . The "no message" control group was coded as 0 .

Finally, we wanted to compare the effect of individual messages. The control group was coded as 1 . The "people like you," "1,000 people like you," "community leaders," and "200 community leaders" conditions were each coded as 0 .

\section{Gender}

A dummy variable for gender was created. Female participants were coded as 1 ; male participants were coded as 0 (female $=65.5 \%, \mathrm{~N}=600$ ).

\section{Age}

Age was an ordinal variable but was treated as a continuous variable for purposes of analysis. Categories included ages $18-24,25-30,31-49,50-65$, and $65+(\mathrm{N}=$ 591).

\section{Income}

Respondents were asked to report their annual household income for 2008. Income was an ordinal variable but was treated as continuous for purposes of 
analysis. Categories included less than $\$ 25,000$ per year, $\$ 25,001-\$ 50,000$ per year, $\$ 50,001-\$ 75,000$ per year, and $\$ 75,000+$ per year $(N=479)$.

\section{Involvement}

A dummy variable was created for involvement. Respondents were asked, "Have you or anyone you know who lives in Allegan County had an unmet transportation need in the past 12 months?" Respondents indicating a positive response were considered involved and coded as 1 ; all others were deemed uninvolved and coded as 0 (involved $=21.5 \%, \mathrm{~N}=587$ ).

\section{Results}

Multiple regression was used to analyze the effect of these messages on verbal support for the policy. Table 2 provides the results. The analysis showed that the "people like you" messages were a statistically significant negative predictor $(\beta=-.12$, $t=-1.99, p=.047$ ) of verbal support for the policy compared to the "no message" condition. While "community leader" messages had a negative effect on verbal support for the policy $(\beta=-.01, t=-.13, p=.90)$, this result was not statistically significant and was close to zero. Thus, the data were not consistent with hypothesis 1a; however, the data were consistent with hypothesis $1 \mathrm{~b}$. The data demonstrated that messages indicating similar others participated in developing a transportation policy significantly decreased support for the policy. Additionally, the data were not consistent with either hypothesis $2 \mathrm{a}$ or $2 \mathrm{~b}$. That is, messages indicating that community leaders participated in developing a transportation policy did not significantly affect support for the policy. ${ }^{6}$

Next, the effect of participation messages was tested on people's behavioral support for the policy. Again, behavioral support for the policy was measured by whether the respondent added his name to the list of transit supporters to be shared with local elected officials. Hypotheses $1 \mathrm{a}, 1 \mathrm{~b}, 2 \mathrm{a}$, and $2 \mathrm{~b}$ were tested using logistic regression. Table 3 provides the results. Compared to the control, none of the messages had a significant effect on behavioral support for the policy. However, the "community leaders" message showed an effect near significance $(p=.07)$. Holding the remaining variables at their modal values, the "community leaders" message increased the probability of providing one's name by 11 percent compared to the control group, providing qualified support for hypothesis $2 \mathrm{a}$. The remaining messages did not have an effect on providing one's name to the list of transit supporters. 
Table 2. OLS Regression Results for Effect of Combined Messages on Verbal Support

\begin{tabular}{|l|c|c|c|}
\hline & \multicolumn{3}{|c|}{ Verbal Support } \\
\hline Variable & $b$ & s.e. & $\beta$ \\
\hline $\begin{array}{c}\text { Participation messages } \\
\text { (Baseline = no message) }\end{array}$ & & & \\
\hline "Community leaders" message & -.02 & .13 & -.01 \\
\hline \multicolumn{1}{|c|}{ "People like you" message } & $-.26^{*}$ & .13 & -.12 \\
\hline Female & $.28^{* *}$ & .10 & .13 \\
\hline Age & $.14^{* *}$ & .05 & .13 \\
\hline Income & -.02 & .05 & -.02 \\
\hline Involved & $.61^{* * *}$ & .11 & .25 \\
\hline Constant & $3.20^{* * *}$ & .29 & \\
\hline $\mathrm{F}$ & $9.24^{* * *}$ & & \\
\hline Adj. $R^{2}$ & .10 & & \\
\hline $\mathrm{N}$ & 455 & & \\
\hline${ }^{*} \mathrm{p}<.05 ;{ }^{* *} \mathrm{p}<.01 ;{ }^{* * *} \mathrm{p}<.001$ & & & \\
\hline
\end{tabular}

Table 3. Logistic Regression Results for Effect of Specific Messages on Behavioral Support

\begin{tabular}{|c|c|c|}
\hline \multirow[b]{2}{*}{ Variable } & \multicolumn{2}{|c|}{ Behavioral Support } \\
\hline & $b$ & s.e. \\
\hline \multicolumn{3}{|l|}{$\begin{array}{l}\text { Participation messages } \\
\qquad \text { (Baseline }=\text { no message })\end{array}$} \\
\hline "Community leaders" message & .51 & .28 \\
\hline "People like you" message & -.03 & .02 \\
\hline Female & -.18 & .21 \\
\hline Age & $.25^{*}$ & .11 \\
\hline Income & -.03 & .10 \\
\hline Involved & $1.43^{* * *}$ & .29 \\
\hline Constant & -.73 & .61 \\
\hline Log Likelihood & \multicolumn{2}{|c|}{-289.19} \\
\hline $\mathrm{N}$ & \multicolumn{2}{|c|}{468} \\
\hline${ }^{*} \mathrm{p}<.05 ;{ }^{* *} \mathrm{p}<.01 ;{ }^{* * *} \mathrm{p}<.001$ & & \\
\hline
\end{tabular}


Finally, although specific hypotheses were not proposed, we were interested in determining the comparative effects of the "people like you" versus "community leaders" messages. "Community leaders" messages had a greater effect than "people like you" messages ( $t=2.35, p=.02$ ) on verbal support for the policy. Additionally, "community leaders" messages had a greater effect on behavioral support for the policy. The probability of adding one's name to a list of policy supporters increased by 12 percent for those exposed to the "community leader" message compared to the "people like you" messages ( $p=.015)$.

\section{Discussion}

This study involved a survey experiment at the conclusion of a year-long participatory process that engaged community citizens and leaders. Whose participation do citizens value most-citizens or community leaders? The results of the study suggest that people do not want "people like them" to develop policies on issues such as public transportation.

In fact, knowing that "people like you" developed a policy actually caused verbal support for the policy to decrease. This result aligns with Goethals and Nelson's (1973) findings that similarity may actually result in adverse consequences. When the public believes they are not knowledgeable about the topic, knowing that similar others participated in policy development can cause support for the policy to decrease.

Also, the analysis found that messages emphasizing community leader participation resulted in more policy support than those emphasizing participation by similar others. This finding supports Kweit and Kweit's (2007) results that perceptions of participation (by community leaders) may have more desirable outcomes than actual participation. At first blush, this finding appears counter to participatory theorists who posit the many benefits of citizen engagement.

However, these findings may not discredit the value of participatory processes, but rather provide data that suggest conditions under which publicity of these processes could garner additional citizen support. Deliberative processes, such as citizen juries, bring community members together, provide them with background facts and myriad arguments, and create dedicated discussion and collaborative dialogue for an extended period. In essence, the citizens who participate leave the process with more expertise than when they arrived-creating citizens who are likely more knowledge about the particular policy than their peers. These results 
suggest that policies developed through these types of citizen engagement processes must make clear to the public that citizen experts assisted in policy development. Merely knowing that participation by the public occurred is not sufficient and can result in adverse consequences such as decreased policy support.

Recent work on attitudes toward democratic decision-making suggests that citizens have a number of negative attitudes about elites; at the same time, citizens have considerable ambivalence about citizen participation in policy-making (Hibbing and Theiss-Morse 2002). The findings in this paper provide evidence that citizens prefer elites to handle decision-making on policies that involve both technical elements and some value judgments. People want those with knowledge to make policy decisions on issues for which they do not possess expertise. They do not want "people like them," without knowledge, to make uneducated decisions. When citizens believe people like them participated in policy-making on local issues (like public transportation), policy support may actually decrease.

Yet, many public engagement processes, including the one in Allegan County, do not limit participation to only elites or the public. Oftentimes, these processes engage both groups, seeking to involve a diverse range of people and perspectives in policy-making. In the current experiment, we studied only the effect of knowing that either similar others or elites participated in policy-making on support for the policy. Perhaps, messages emphasizing that a diverse group of citizens and elites had the opportunity to participate in policy-making would increase support for the policy and the legitimacy of the process. These messages would indicate the true nature of the processes that usually occur in participatory transit planning. Future research could address this possibility by testing messages that include both citizens and elites.

Media coverage could also affect perceptions of participation. Because this study received little newspaper coverage (i.e., two articles total, one per local paper) two months before this experiment occurred, it is unlikely the media affected perceptions of the public involvement processes that occurred prior to this study. However, for other public transit involvement efforts, it is possible that media coverage could shape public perceptions (see Dearing and Rogers 1996; lyengar and Kinder 1987; McCombs and Shaw 1972 for a discussion of agenda setting). That is, media coverage could affect perceptions of who and how many participated, whether these individuals were knowledgeable, and the extent to which all citizens had the opportunity to voice their opinions. Future research could assess the effect of how 
participatory efforts are framed by the media on resulting public support for the policy.

Finally, we believe there is a possibility that having the opportunity to participate may increase support prospectively and decrease it retrospectively. That is, there may be a difference between having the opportunity to participate in the future and knowing that similar others had the opportunity to participate in the past. For example, if I have the opportunity to participate in the future, I may choose to participate and influence the outcome. In this case, I may like the policy better because I like the opportunity to participate generally. However, if I know only that people had the opportunity to participate in the past (as was the case in the current study), I can no longer influence the outcome. Also, when I know that nonpolicymakers, like me, have designed the policy, my support may be lower than it would have been if policymakers had designed the policy. The difference between prospective and retrospective opportunity to participate warrants future testing. However, the implication for transit professionals is to consider that, given the current study, retroactive opportunity can have negative consequences for support of the policy. There is still the possibility that proactive participation can increase support for the policy.

\section{Conclusion}

This study provided one of the few survey experiments conducted in the context of an actual transportation campaign on the effects of participation messages on support for an actual policy. The results provide further evidence about the conditions under which participatory messages may be influential as well as some of the limitations of perceptions of participation. Future studies may consider the following to improve on the limitations in this study.

First, this study occurred in a single rural county. The same results may not hold in a different state or type of area, such as an urban community. Therefore, replication in different types of communities would increase the external validity of the results.

Second, a couple of assumptions were made in this study. First, we assumed citizens are not knowledgeable about public transit issues. Second, we assumed citizens do not feel that they possess the expertise to develop transit policies. Future studies might consider a more rigorous test of these assumptions. 
Third, the messages tested in this study were limited to the distinction between similar others and community leaders. However, many participatory processes may engage both. Additionally, at the core of deliberative processes is the effort to engage a range of different citizens. Therefore, future studies may seek to develop a variety of messages to test whether emphasizing other types of dissimilarity are effective at eliciting citizen support for policies.

Finally, our study employed a retrospective message. That is, we informed people that similar others had participated in policy-making. This retrospective message removed the opportunity for future participation from those who we contacted. Perhaps, our findings of decreased policy support hold true only for retrospective messages. If so, messages that provide people with an opportunity to voice their opinions may be effective in increasing support for transit policies. The important implication for transit professionals is the timing and framing of such messages. Those that promote retrospective participation should emphasize community leader participation and those promoting prospective participation need to be tested.

We have found that who participates matters. Citizens do not want "people like them" developing policies. Transit professionals should be cautious when promoting deliberative and participatory processes. Messages focusing on similarity alone could have a boomerang-type effect by decreasing support for public policies.

Rather, transit professionals should develop messages that emphasize the knowledge or expertise of those involved in participatory processes. In addition, it is possible that citizen's would find value in knowing that they had the opportunity to participate, given Kweit and Kweit's (2007) findings; however, the extent to which transit professionals promote this engagement should be attempted with caution until the nuances of how to design the messages receive further testing.

At the very heart of participatory transit planning are democratic ideals of giving citizens a voice in determining public services that will best meet community needs. As transit professionals know, engaging the public in participatory processes requires extensive resources. Maximizing the efficiency and effectiveness of these efforts becomes important as transit agencies seek to garner public support for the plans that result from these participatory processes. This study suggests that promoting the participation and contribution of elites is critical to securing public support of transit plans once they have been developed. 


\section{Endnotes}

${ }^{1}$ It is possible that some individuals may prefer not to engage in policy-making themselves, yet want the opportunity to be involved. However, we believe that these individuals would support a policy by knowing that the general public was encouraged to participate because they, as members of the general public, had the opportunity to provide input. However, our findings reveal that knowing members of the community participated in policy-making actually decreased support for the policy-suggesting that, while some people may fall into the category of not wanting to participate but wanting the option, the majority of people prefer to have elites, or knowledgeable others, engage in policy-making on their behalf for issues such as public transportation.

${ }^{2}$ We also explored a second independent variable: number of participants (200 or 1,000 v. no number). We acknowledge this creates an ecological confound in the design, as the number of participants in the messages is not kept constant. In the community leader by number of participants condition, the message referred to 200 community leaders who participated in policy development. However, in the community member by number of participants condition, the message referred to 1,000 community members who participated in policy development. While this inconsistency is not ideal, the study was part of a larger transit project in a community, and the design used the actual numbers of different types of participants. Since 1,000 community leaders did not participate in the process, it would be unethical to report this number, and vice versa.

${ }^{3}$ No major statistical differences were found between the control group and individual messages on dependent variables.

${ }^{4}$ After conducting an archive search for articles covering the public involvement processes that occurred, only one article in each paper was found. These two articles discussed the input sessions in Phase 3 and appeared in September 2009. Because the media coverage of the public engagement processes prior to the current survey was limited, the public was unlikely affected by the media, allowing the manipulation to have stronger effects.

${ }^{5}$ The control condition allowed assessment of any previous question effects.

${ }^{6} \mathrm{An}$ additional analysis of the individual messages found that only the "people like you" message $(\beta=-.12, t=-2.03, p=.04)$ was a significant negative predictor of verbal support for the policy compared to the control group, while the "1000 people like you" message ( $\beta=-.08, t=-1.42, p=.16)$, the "community leader" message ( $\beta=$ 
$.05, t=0.91, p=.36)$, and the "200 community leaders" message $(\beta=-.07, t=-1.14$, $p=.26$ ) were not, controlling for other covariates in the model.

\section{References}

Allegan County Transportation. 2010. Allegan County Transportation Annual Report. Retrieved January 22, 2012, from http://www.allegancounty.org/docs/ AnnualReport/ 2010/TD2010_AnnualReport.pdf.

Beierle, T. C. 1999. Using social goals to evaluate public participation in environmental decisions. Policy Studies Review 16(3/4): 75-103.

Bryne, D. 1971. The Attraction Paradigm. New York: Academic Press.

Cialdini, R. B. 2001. Influence: Science and Practice (4th ed.). Needham Heights, MA: Allyn \& Bacon.

Disability Network/Lakeshore. 2012. Disability Network/Lakeshore Transit Reports. Retrieved January 20, 2012, from http://www.dnlakeshore.org/transitreports. html.

Ely, J. H. 1980. Democracy and Distrust. Cambridge: Cambridge University Press.

Emswiller, T., K. Deaux, and J. E. Willis. 1971. Similarity, Sex, and Requests for Small Favors. Journal of Applied Social Psychology 1: 284-291.

Evans, F. B. 1963. selling as a dyadic relationship. American Behavioral Scientist 6(7): 76-79.

Fishkin, J. S. 1995. The Voice of the People: Public Opinion and Democracy. New Haven, CT: Yale University Press.

Fishkin, J. S. n.d. Deliberative polling. Retrieved February 10, 2010, from The Center for Deliberative Democracy, http://cdd.stanford.edu/polls/docs/ summary/\#exec.

French, J. R. P., and B. Raven. 1959. The bases of social power. In D. Cartwright and A. Zander, Group Dynamics. New York: Harper \& Row.

Furnham, A. 1996. Factors relating to the allocation of medical resources. Journal of Social Behavior and Personality 11: 615-624.

Garner, R. L. 2005. What's in a name: Persuasion perhaps? Journal of Consumer Psychology 15(2): 108-116. 
Goethals, G. R., and R. E. Nelson. 1973. Similarity in the influence process: The beliefvalue distinction. Journal of Personality and Social Psychology 25(1): 117-122.

Hibbing, J. R., and E. Theiss-Morse. 2002. Stealth Democracy: American's Beliefs about How Government Should Work. Cambridge: Cambridge University Press.

Hibbing, J. R., and E. Theiss-Morse. 2001. Process preferences and American politics: What the people want government to be. American Political Science Review 95(1): 145-153.

Irvin, R. A., and J. Stansbury. 2004. Citizen participation in decision making: Is it worth the effort? Public Administration Review 64: 55-65.

Jones, E. E., and H. B. Gerard. 1967. Foundations of Social Psychology. New York: Wiley.

Keele, L. 2007. Social capital and the dynamics of trust in government. American Journal of Political Science 51: 241-254.

Kweit, M. G. and R. W. Kweit. 2007. Participation, perception of participation, and citizen support. American Politics Research 35(3): 407-425.

Michigan Department of Transportation. 2010. Michigan's FY 2011-2014 State Transportation Improvement Program. Retrieved January 20, 2012, from http://www.michigan.gov/ documents/mdot/mdot_stip_4_public_participation_333552_7.pdf.

Prothro, J. W., and C. M. Grigg. 1960. Fundamental principles of democracy: Bases of agreement and disagreement. Journal of Politics 22(2): 276-294.

Putnam, R. D. 1995. Blowing alone: American's declining social capital. Journal of Democracy 6(1): 65-78.

Rawls, J. A. 1971. A Theory of Justice. Cambridge: Harvard University Press.

Suedfeld, P., S. Bochner, and C. Matas. 1971. Petitioner's attire and petition signing by peace demonstrators: A field experiment. Journal of Applied Social Psychology 1: 278-283.

Suls, J., R. Martin, and L. Wheeler. 2000. Three kinds of opinion comparison: The triadic model. Personality and Social Psychology Review 4(3): 219-237.

Tyler, T. R. 1990. Why People Obey the Law. New Haven, CT: Yale University Press. 
Tyler, T. R., K. Rasinski, and N. Spodick. 1985. The influence of voice on satisfaction with leaders. Journal of Applied Social Psychology 15: 700-725.

U. S. Department of Transportation. 2007. Title VI and Title VI- Dependent Guidelines for Federal Transit Administration Recipients. Retrieved January 20, 2012, from http://www.fta.dot.gov/documents/Title_VI_Circular_4702.1A.pdf.

\section{About the Authors}

Geneviève RISNER (risner@bus.msu.edu) earned her Ph.D. from Michigan State University in Communication and is the Director of the Ernst \& Young Communication Center in the Accounting and Information Systems Department at MSU. From 2003-2008, she was the Director of Public Policy for Disability Network/Lakeshore, a disability advocacy organization, where she specialized in public transit policy and community organizing. Her research interests include persuasion, survey methodology, participatory decision-making, and framing.

Daniel BerGan (bergan@msu.edu) earned his Ph.D. at Northwestern University in Political Science and is Assistant Professor in the Department of Communication and James Madison College at Michigan State University. From 2005-2007, he was a postdoctoral researcher at Yale University's Institution for Social and Policy Studies. His research interests include a variety of political communication topics, including grassroots lobbying, issue ads, and civic education. He has published articles in a variety of scholarly journals, including Public Opinion Quarterly, American Politics Research, and Presidential Studies Quarterly. 